Session 3130

\title{
Outcomes Assessment: Developing an Electronic Assessment Database as a Model for Collection and Analysis of Data
}

\author{
Joni E. Spurlin, Sarah A. Rajala, Jerome P. Lavelle, O. Jerome Hoskins \\ Office of Academic Affairs \\ College of Engineering \\ North Carolina State University \\ Campus Box 7904 \\ Raleigh, NC 27695-7904
}

\begin{abstract}
As the ABET process in each institution moves toward outcomes assessment, it pushes each program to develop and implement its outcome assessment plans. Assessment plans document how programs will gather data, interpret the findings, and use the results to make improvements in programs, curricula, and resources. The ABET team at North Carolina State University (faculty from each engineering discipline along with assessment-knowledgeable personnel) has developed a model that academic programs within the College of Engineering use to determine what data to gather, where to obtain the data, and what criteria may be most appropriate when interpreting the data.
\end{abstract}

This paper presents the model and the processes by which our programs collect data, examine processes already in place at the institution, and determine redundancies as well as omissions in those processes, methods, and data. This paper also describes the North Carolina State University College of Engineering's Electronic Assessment Database website (www.engr.ncsu.edu/assessment) which illustrates the on-going process of assessing and improving student learning using this model. The website provides a filter for the expanse of all possible data to help faculty conveniently and effectively access the data. It also provides ways to link programmatic outcomes to curriculum assessment methods including classroom assignments, course portfolios, and capstone design projects.

\section{Regional and Programmatic Accreditation}

North Carolina State University falls under the accreditation auspices of the Commission on Colleges of the Southern Association of Colleges and Schools (SACS). SACS has been a leader in the field of assessment and institutional effectiveness. The Commission on Colleges is currently reviewing the way it evaluates institutions for accreditation. The Commission on

"Proceedings of the 2002 American Society of Engineering Education Annual Conference \& Exposition Copyright (c) 2002, American Society of Engineering Education 
Colleges is working on a new set of criteria and procedures that will be even more heavily based on assessment processes and on providing evidence that the institution "maintains clearly specified educational objectives that are consistent with its mission and appropriate to the degrees it offers." "As part of the new accreditation process, each institution must meet the Core Requirements, and the Comprehensive Standards on institutional effectiveness, as in the examples given below:

Core Requirements: The institution engages in ongoing, integrated, and institution-wide research-based planning and evaluation processes that incorporate a systematic review of programs and services that (a) results in continuing improvement and (b) demonstrates that the institution is effectively accomplishing its mission. See Core Requirement 5, pg. $8 .^{1}$

Comprehensive Standards: The institution identifies expected outcomes for its educational programs and its administrative and educational support services; assesses whether it achieves these outcomes; and provides evidence of improvement based on analysis of those results. See Comprehensive Standard on Institutional Effectiveness, pg. $11 .{ }^{1}$

Like SACS, the Accreditation Board for Engineering and Technology (ABET) has also moved toward an outcomes assessment process. Consequently, the concept of outcomes assessment is new for many faculty within engineering programs. All general comprehensive reviews beginning 2001-02 have been conducted under the new outcomes-based criteria (Engineering Criteria 2000 or EC2000). EC2000 states that each program must develop program educational objectives, program outcomes, and develop methods to assess each. ${ }^{2}$

Authorities in the field of assessment have asserted that regional or programmatic accreditation cannot be treated as something "different" or something that is completed by a few faculty members. Data collection should not be done in the sterile environment of accreditation. Rather, it must be integrated into the entire institutional framework of assessment to be effective. ${ }^{3,4,5}$ "The biggest challenge for assessment with respect to serving dual purposes is to generate information based on locally developed methods that can be reported to external audiences in meaningful ways." 4

Knowing that NC State's engineering programs would come under an ABET and a SACS review during the spring and fall of 2004, the engineering programs began to develop plans and outcomes assessment processes soon after the last accreditation visit in the fall of 1998. As part of the assessment development, the programs decided that the processes must not only met regional and programmatic accreditation needs, but the processes must also be of value to the faculty. A search of the engineering education literature showed that few engineering programs had a comprehensive system for measuring program results in terms of student learning outcomes.

As a first step the College of Engineering developed more specific guidelines for writing program educational objectives. ${ }^{6}$ As efforts continued, it became clear that the knowledge and

"Proceedings of the 2002 American Society of Engineering Education Annual Conference \& Exposition Copyright (C) 2002, American Society of Engineering Education 
language of assessment was varied and that developing a common base from which to communicate was needed. As the discussions continued, the ABET team developed a model to describe what assessment methods were needed and what data should be collected. This model allowed the faculty to be able to communicate with each other, and to discuss the methods of assessment they have in common while still maintaining the autonomy needed for program differences.

\section{Model for Outcomes Assessment}

Figure 1 provides an overview of the model developed by the NC State ABET team. The model can be seen to have four major parts:

1. defining program mission, objectives, and outcomes;

2. developing an assessment plan to assess the program objectives and outcomes with linkages to curriculum issues and implementation;

3. gathering the data into a database; and

4. interpreting the data to determine program effectiveness and implementing program improvements.

Each of the four major parts of Figure 1 is explained in more detail below.

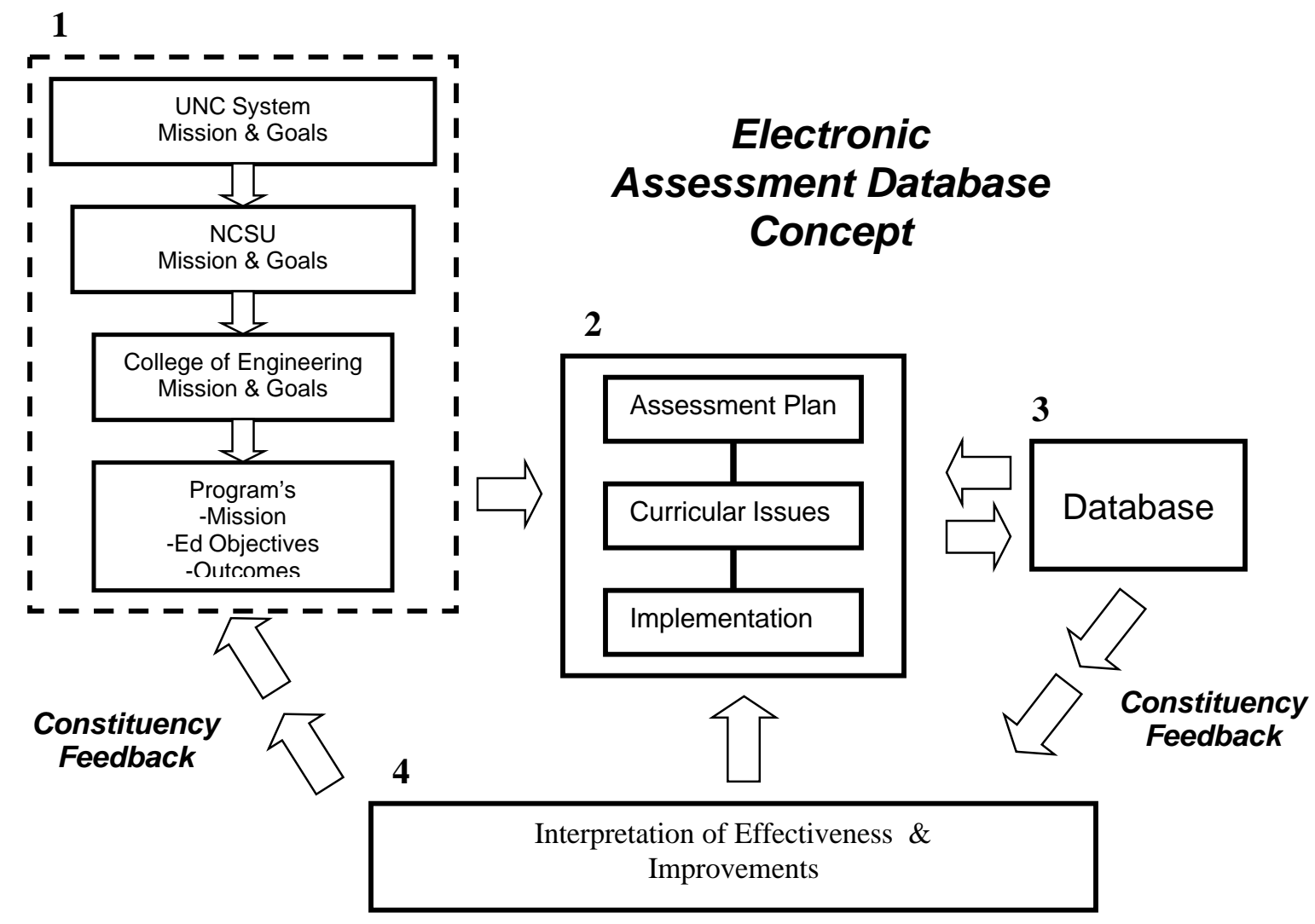

Figure 1: Electronic Assessment Database Concept

"Proceedings of the 2002 American Society of Engineering Education Annual Conference \& Exposition Copyright (c) 2002, American Society of Engineering Education 


\section{Defining Program Mission, Objectives and Outcomes}

Regardless of why a program is assessing its effectiveness for improvement, each program must develop its unique mission, educational objectives, and outcomes. The program's mission, objectives, and outcomes must relate to the institutional mission and goals. Depending on the complexity of the infrastructure of the institution, several levels of missions and goals may have to be related. For example, at NC State, each program had to relate their unique goals to the College of Engineering's mission and goals, to the NC State University's mission and goals and ultimately to the University of North Carolina system-wide mission and goals. In Carter, Brent $\&$ Rajala $^{5}$, a process is described for defining the program mission, objectives, and outcomes consistent with EC 2000 Criterion 2.

\section{Developing an Assessment Plan to Assess the Program Objectives and Outcomes with Linkages to Curriculum Issues and Implementation.}

Figure 1 illustrates that the program mission, objectives, and outcomes must also relate to the program's assessment plan. The assessment plan describes how the outcomes may be assessed, and related to the program's curriculum and course outcomes. The plan may also describe how the outcomes will be taught and implemented in the program. Some of the outcomes may be implemented outside the curriculum, including student service activities, outside employment, and other co-curricular activities.

The model shows what should be included in an assessment plan; what types of data should be collected, how to link program outcomes to course outcomes, how to link course assessment to program outcomes assessment, and how to ensure that the outcomes are not only assessed but are taught in the curriculum. Banta, McGordy, and others have described formats for assessment plans in the literature. ${ }^{4,7,8,9}$ The contribution that this paper describes is a process to ensure there are linkages with curriculum issues.

Information in NC State's College of Engineering Assessment Plans includes the following:

- Program Outcomes: Outcomes describe what the academic department intends for students to know (cognitive), think (affective, attitudinal), or do (behavioral, performance, psychomotor) when they have completed a given educational program.

- Implementation: How/where the program will implement or teach the concepts related to each outcome.

- Assessment Plan for data collection: Brief description of how each outcome will be assessed, who will collect the data, and how it is expected to be used. When writing the assessment plan, include the following:

o who (who is being assessed and who will judge that assessment)

o what (what method is being used)

o when (when will assessment take place)

o where (in which course or in what timeframe will the assessment occur)

o other descriptions as needed.

"Proceedings of the 2002 American Society of Engineering Education Annual Conference \& Exposition Copyright $@$ 2002, American Society of Engineering Education 
- Relationships: How the program outcomes related to ABET EC2000 Criterion 3 and to ABET EC 2000 Criterion 8.

The program outcomes and objectives should be directly linked to the curriculum and to course outcomes/objectives (see Figure 2). Each course in the program will typically have three to five course outcomes/objectives related to some of the program outcomes. Not all courses will be mapped to all program outcomes. A graphical mapping of the relationship is useful: one side of the grid could be the program outcomes, the other side of the grid could be course outcomes, inside the grid could show how they are assessed, e.g., portfolio, test, survey. Rose-Hulman Institute has an interesting mapping system where each course objective is mapped to each program objective using three questions:

- "The objective is explicitly stated as being a learning objective for this course."

- "Students are asked to demonstrate their competence on this objective through homework, projects, test, etc."

- "Students are given formal feedback on their performance on this objective." 10

\section{Links to Curriculum}

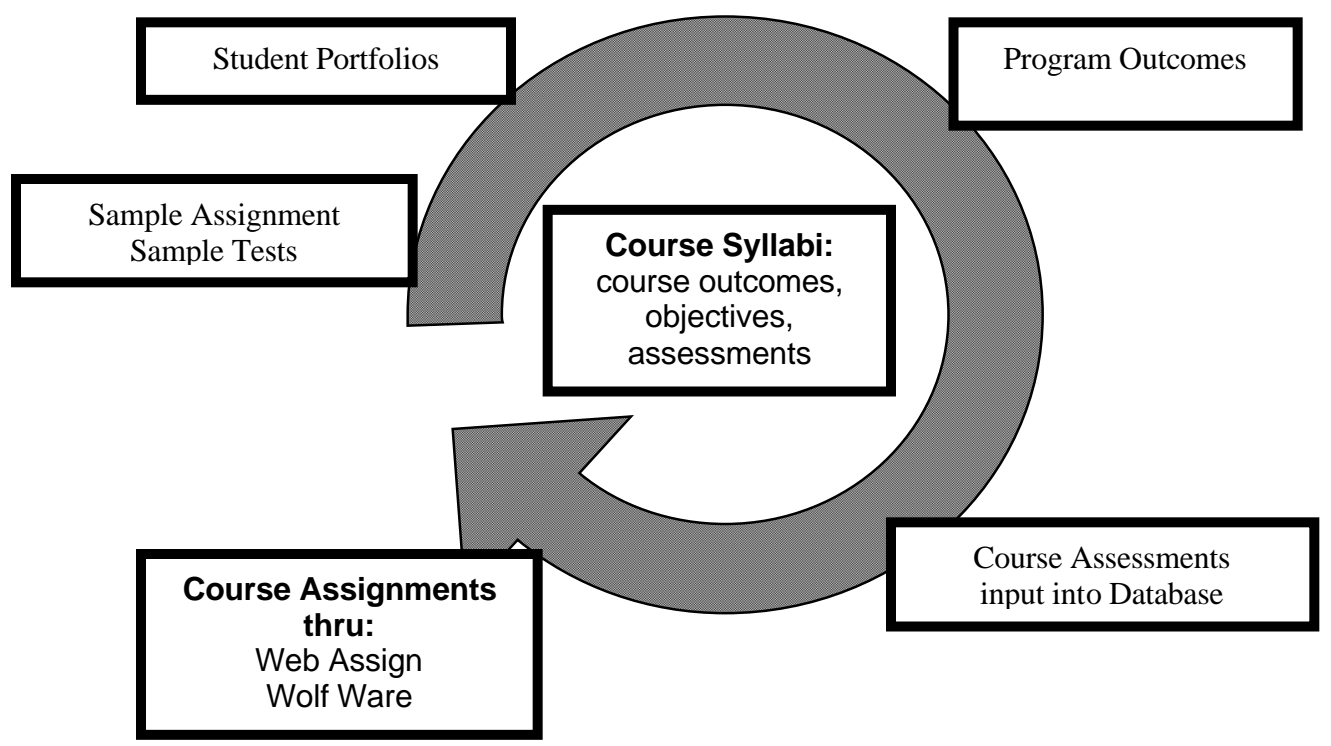

Figure 2: Curriculum Model

\section{Gathering the Data into a Database}

In order to document how outcomes have been assessed and to understand how effective the curriculum has been, data must be collected. Assessment methods, and therefore the data collected, are selected to measure effectiveness of each learning outcome, and to provide data

"Proceedings of the 2002 American Society of Engineering Education Annual Conference \& Exposition Copyright (C) 2002, American Society of Engineering Education 
from multiple points of contact. Examples of such varied sources of attaining this data include potential students to incoming freshmen to senior to alumni, as well as from faculty and staff to the program's constituency. Various types of measurements may be used, including surveys, interviews, management information system data, and testing. Others have discussed the advantages and disadvantages of specific assessment methods and data collection techniques. ${ }^{4,11}$

The NC State model includes eight categories of data in the common database (see Figure 3). This categorization shows how outcomes can use data from multiple sources. Data gathering is based on several underlying principles. 1) Data should be related to outcomes. Faculty should not focus on all possible data that may be available, but should focus on the data that is directly related to each of the program's outcomes. 2) Multiple measures should be used to triangulate data, to bring about the best understanding of how well each outcome is met. 3) Data points should be as specific as possible to allow the faculty to be able to make decisions about a program's strengths and weaknesses. 4) The timeline in which data is collected should be evaluated. Once baseline data has been established, and if no changes are to be made to the program, then some measures/data may not need to be collected every year.

\section{DATABASE}
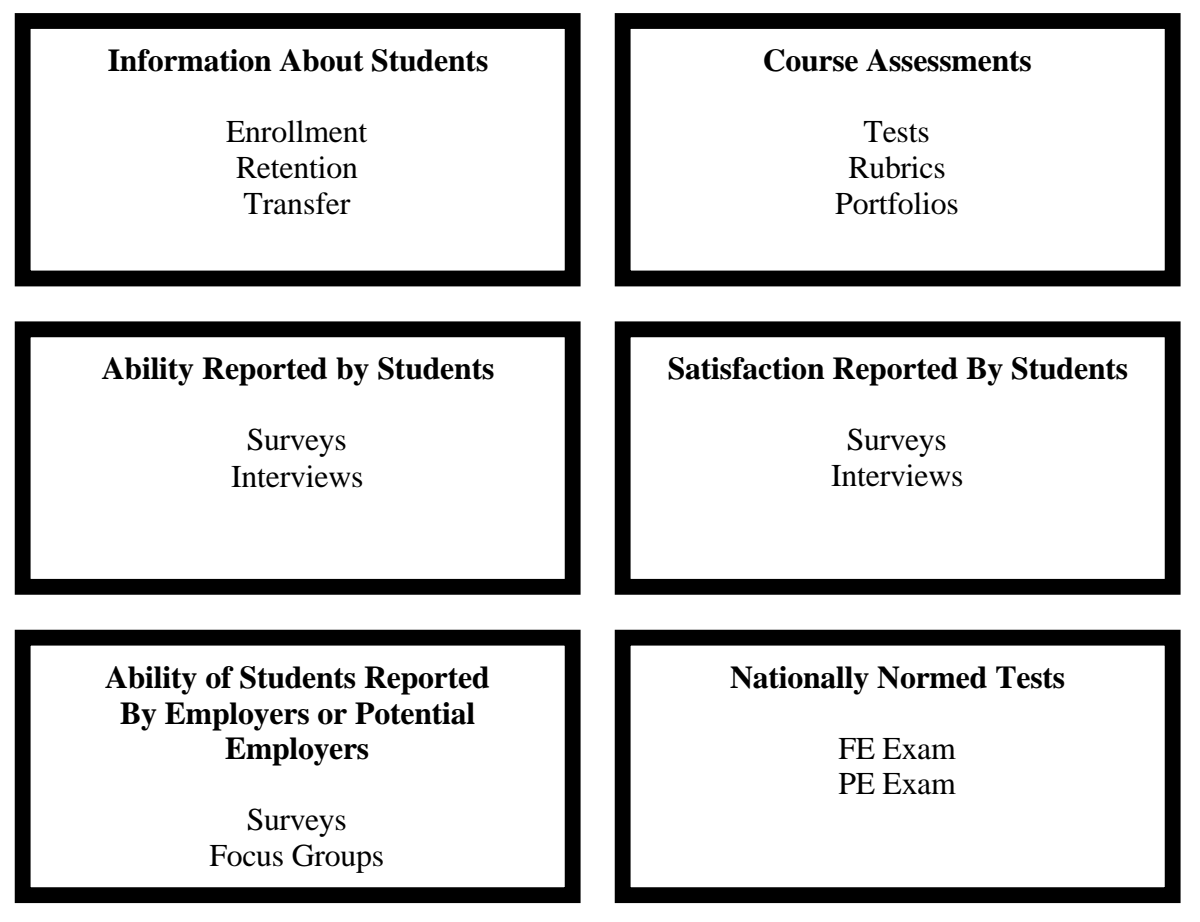

Information about Faculty \& Courses

Information about Facilities \& Equipment/Tools

Faculty/Student Credit Hours Number of Terminal Degrees Summary Data - Student

Quantity

Quality

Figure 3: Database Structure

"Proceedings of the 2002 American Society of Engineering Education Annual Conference \& Exposition Copyright (c) 2002, American Society of Engineering Education 
In the following sections is a description of each category of database structure in the model and where each type of data may be found or how it can be generated. In general, the first place to look for any data is with the institution's institutional research office, assessment office, or planning office. It is important to know who conducts surveys on campus - institutionally, or some subset of the organization. For example, the technology/computer support department may conduct surveys about the use of technology on campus and may have data related to student's "ability to use the techniques, skills, and modern engineering tools necessary for engineering practice" (EC 2000 Criterion 3k). Larger institutions may have a center for survey research, which may have data from multiple surveys over a number of years. The campus committee leading a regional accreditation self-study may also be a good resource for understanding the location of data.

\section{$\underline{\text { Information about the Student }}$}

This data can be used for outcomes or even program objectives related to retention of students, issues related to students transferring from one engineering program to another and/or issues related to understanding who is entering into and graduating from the program. These data also relate to EC 2000 Criterion 1: "The quality and performance of the students and graduates are important considerations in the evaluation of an engineering program. The institution must evaluate, advise, and monitor students to determine its success in meeting program objectives. The institution must have and enforce policies for the acceptance of transfer students and for the validation of courses taken for credit elsewhere."

Typically, the kind of student information that can be found through the university's institutional research office include the following:

- SAT scores

- ACT scores

- High School GPA and rank

- Test scores at entry

- Institutions where the students transferred from and credit hours transferred

- Enrollment status of students at a given semester

- Gender and ethnicity numbers and ratios

- Courses taken and grades

- Semester, current or graduating GPA

- Participation in cooperative educational and/or study abroad/exchange experiences.

- Honor courses taken

- Semester credit hour load, by semester

- Semesters withdrawn

- Suspension/Expulsion data

- Academic minors

- Second degrees (dual degrees)

"Proceedings of the 2002 American Society of Engineering Education Annual Conference \& Exposition Copyright (c) 2002, American Society of Engineering Education 


\section{Ability Reported by the Students}

Students can be asked to assess their abilities and perceptions of how well they meet the program outcomes. This may be done at any point in their educational experience, but is typically captured during the last semester of their senior year. Some institutions also collect information from alumni as they look back on their abilities. Some ask alumni to relate their skills to the activities they are expected to perform during their first few years of employment. This type of data is easier to collect than other types and may be collected at the institutional level. Student's self-assessment of their ability provides valuable information, but is only one data point and should not be used as the only data to make judgments about whether that outcome has been met. In addition, one may need to select questions on the survey that specifically relate to program outcomes. A survey can produce a significant amount of data, especially institution wide surveys; all the data may not be related to defined outcomes.

Many institutions conduct a "senior" survey. The engineering program faculty may be able to add questions to the institutional senior survey that more closely align with their program outcomes. For example, students may be asked to rate their ability or their preparation from "poor" to "excellent" on "their ability to analyze data." (Related to ABET Criterion 3b.)

The program faculty or program chair may interview graduating seniors as part of the exit process for graduation. This interview may consist of paper and pencil surveys or focused interview questions. Whoever conducts the focused interview should take careful, unbiased notes on the input from the students.

Many institutions also conduct an "alumni" survey. As in the case with the senior survey, engineering program faculty may be able to add questions to the institutional alumni survey that more closely align with their program outcomes. Typical challenges when surveying alumni is obtaining accurate current residence addresses and in encouraging responses. One of the best sources of data for the current addresses of alumni, outside of the department, is the institution's alumni office. In sending a mailed survey, a personal note from a faculty member that the graduate may identify with, is often effective in getting good response rates. Phone interviews with alumni may also provide a better response rate.

Surveys at the freshmen, sophomore or junior level may be used to examine the "value added" of the educational experience as it relates to outcomes. Also, surveys completed by the students at the end of a cooperative educational experience may provide data about their abilities as they have actually performed them.

\section{Ability of the Student/Graduate as Reported by Potential Employers or Employers}

If gathered correctly, input from employers can be valuable in assessing the outcomes of the program. Data can be collected from alumni's employers, corporate recruiters on campus, or from cooperative education supervisors. Some institutions may conduct an "employer" survey periodically. If so, program faculty may be able to add questions to this survey. One of the major challenges with surveys of employers is the difficulty in obtaining an accurate sample.

"Proceedings of the 2002 American Society of Engineering Education Annual Conference \& Exposition Copyright (c) 2002, American Society of Engineering Education 
Therefore, program faculty may need to work closely with institutional research personnel to develop a method for collecting employer surveys.

Corporate recruiters interview summer interns and graduating senior students on the campus. They may be able to provide information about the quality of the current students or program graduates. Recruiters can be surveyed or interviewed by program faculty or chair. Focus groups provide another method for gathering data from recruiters. Leonard has published an article which "describes a protocol that engineering faculty can use to plan and conduct focus group sessions with corporate recruiters coming to their campuses." ${ }^{12}$

Some programs have cooperative education as a part of their curriculum. The supervisors at the cooperative education site can provide valuable information about the students. These supervisors can be surveyed or interviewed. The only drawback is that some of the students have cooperative experience at the beginning of their engineering education and therefore this data may not be directly related to the outcomes, but may provide more "process" data.

Industry representative may be used to judge the capstone senior design project. They may work closely with the seniors during this project and may be able to provide valuable feedback on the quality of the graduate. Faculty who work with industry representatives can ask the representatives to complete a survey rating the graduates at the end of the senior design project discussion.

\section{Course Assessment}

The assessment plan should list the courses most closely related to each program outcome. Faculty in these courses may already have developed assessment methods that can be used for program assessment or there may be tests, papers or reports which can be used for assessment. For example, final exam questions may be extracted to determine the percentage of students who can answer questions related to a specific topic. Papers may also be analyzed using a rubric ${ }^{\dagger}$ that has delineated specific topics related to the program outcomes. Portfolios ${ }^{\ddagger}$ are becoming a popular method of assessment and can provide a rich supply of data. The development of electronic technologies for creating and storing portfolios has increased the possibilities for this method. Portfolios are judged by one or more faculty members in the department or college, or by one or more outside experts in the field. A grading scale should be developed that allows for assessment of the program outcomes. (See the work of faculty from the University of Florida and Virginia Tech who have developed a website that explains how to conduct portfolio assessment in engineering courses ${ }^{13}$.) Assessment data related to math or science courses may be available from faculty who teach the basic science courses such as calculus, basic physics and basic chemistry courses.

\footnotetext{
${ }^{\dagger}$ A rubric is a guideline or description of characteristics related to expected quality of performance - these are typically seen for evaluating writing skills. Each element of a rubric describes what is expected of the student at several possible performance levels.

${ }^{\ddagger}$ Portfolios are collections of a student's work. This work may represent work for a specific course or work over the entire undergraduate experience.

"Proceedings of the 2002 American Society of Engineering Education Annual Conference \& Exposition Copyright (c) 2002, American Society of Engineering Education
} 
Faculty who teach senior engineering courses may be used to gather data on many of the program's outcomes. For example, the capstone senior design course may be use to gather data related to, not only engineering ability, but also on ethical consideration, impact of engineering in global and social context, and how well students function on multidisciplinary teams.

As shown in Figure 3, the data collected in some courses may already be available on the computer through electronic coursework submissions using tools such as Web CT, Blackboard, or Web Assign. The coursework can be captured at the end of each semester and put into the database, as relevant.

\section{Nationally Normed Tests}

Standardized exams, as an assessment method, can appear to be "easy." However, the department needs to be able to use the results of such tests for improvement. To do so, the department may need to have the subscores broken into a level that is useable. For example, the Fundamentals of Engineering Examination has subscores in more than 20 areas and can give a broad overview of weaknesses. The faculty would then need to examine these weaknesses further in specifically related courses or in conjunction with other related data. The Fundamentals of Engineering Examination results can be found at your state Board of Examiners for Engineers and Surveyors.

\section{Satisfaction Reported by Students}

Many programs gather data on satisfaction to strengthen their outcomes assessment. Although not directly related to performance outcomes, student satisfaction with courses, campus climate, faculty, facilities, and equipment, may indicate indirect problems or challenges that the program may be able to improve. In addition, this type data can help to support the evaluation of ABET EC 2000 Criterion 6: "Appropriate facilities must be available to foster faculty-student interaction and to create a climate that encourages professional development and professional activities."

As discussed above, many institutions conduct a "senior" survey. The engineering program faculty may be able to add questions to the institutional senior survey that more closely align with their program outcomes and satisfaction with other academic and non-academic concerns. Similarly, students may be interviewed as part of their exit process for graduation or be part of a focus group discussion on their satisfaction. Focus groups of students, staff, faculty, employers, and community agencies can also provide data about their satisfaction with the program, curriculum, and other non-academic areas.

\section{Information about Faculty and Courses}

Information about the faculty (ABET Criterion 5: "The faculty is the heart of any educational program.") can consist of their qualifications, the number of courses they teach, the number of credit hours they carry, and their overall performance as rated by student through course evaluations.

"Proceedings of the 2002 American Society of Engineering Education Annual Conference \& Exposition Copyright $@$ 2002, American Society of Engineering Education 
The kind of data that can be found through the institution's institutional research office include the following:

- Credit hours taught for each semester, by department, course or instructor

- Number of full-time and part-time faculty, by rank, by headcount, ethnicity, and gender

- Student /faculty ratio

- Workload of faculty

- Salary ranges for faculty by specific ranks, gender and ethnicity

The institution's assessment office or dean's office may have a summary of overall evaluation of all faculty within a department on teaching effectiveness as measured by a survey completed by students on faculty or course evaluations. These overall summaries will not identify any one faculty, but will give an overall view of teaching as seen by the students.

Faculty qualifications may be found at the dean's office or the person in charge of qualifications at the institutions. This data must be maintained for other purposes, so should be readily available for overall statistics, such as percentage of faculty with terminal degrees in engineering.

Information About Facilities, Equipment, Tools

ABET Criterion 6 requires the program to document that the classrooms, laboratories, and equipment are adequate to accomplish the program objectives. The data will include the numbers of classrooms, types of laboratories, and equipment available for student's use. Numbers of classroom and laboratories can be found with those who track this at the institution, such as accounting or maintenance offices. Satisfaction with the classroom, laboratories and equipment can be found in the surveys mentioned above.

\section{Interpretation of Effectiveness and Improvements}

The fourth part of the model (refer back to Figure 1) is the interpretation of effectiveness and documentation of curricular or program improvement. This is an important step in the assessment process because in it a program documents what the data means, how it proves the program's effectiveness, and how faculty use it to make improvements to the program.

The model suggests ways to find and gather data, but what is of utmost importance is to use the data to make improvements to the program. As will be seen in the following section, the implementation of the model to develop a central website allows for the gathering of the data into one place. This website provides access to all faculty, at all times, so that the faculty can make interpretations when they need the data. It may be at a curriculum meeting or a meeting to discuss the improvement of the facilities, that this data can be used. In terms of accreditation needs, a faculty committee should come together to interpret the data. This interpretation can then be shared with faculty from other programs or the program's constituency. The data can be interpreted ad-hoc or at least once per year. For example, requiring the program to submit an

"Proceedings of the 2002 American Society of Engineering Education Annual Conference \& Exposition Copyright (C) 2002, American Society of Engineering Education 
annual report that documents any changes in the assessment plan, summarizes data findings and actions to be taken, may be a useful step in the process.

Use of rubrics to define proficiency for the outcome, is another way of determining if the data is showing effectiveness. The following example of a program outcome has a three level rubric that can be used to give an overall judgment about how well students are meeting this outcome, after they have examined all the relevant data.

Example:

Program Outcome: By the time they graduate, engineering students will be able to show that they can employ general principles, theories, concepts, and/or formulas from mathematics, in the solution of engineering problems.

Possible Rubric Scores:

Excellent: student can define and describe the pertinent principles and appropriate assumptions, theories, concepts, and/or formulas; explain how they are appropriate to the problem; and demonstrate how they have been applied in the solution of the problem.

Average: student can define and describe pertinent principles but can not explain how they are appropriate to the problem or can not demonstrate how they have been applied in the solution of the problem.

Poor: student cannot define and describe the pertinent principles, and appropriate assumptions, theories, concepts, and/or formulas; explain how they are appropriate to the problem; and demonstrate how they have been applied in the solution of the problem.

\section{Implementation of the Assessment Model: Developing an Electronic Database on the Web}

A database is defined as a "collection of data arranged for ease and speed of search and retrieval". ${ }^{14}$ Once the model was developed, the NC State Team began to create a database website based on the model that would enable easy retrieval of assessment data. The basic design was to be able to push a button and see all the data related to a specific outcome; to be able to push a button and see the course outcomes that relate to a specific program outcome; and to push a button and see an overview of improvements made to a program related to a specific program outcome. The NC State College of Engineering's Electronic Assessment Database website allows faculty to systematically collect and analyze data, whether in a specific course or information collected across courses or other types of assessment data. It also provides ways to link programmatic outcomes to curriculum assessment methods including classroom assignments, course portfolios, and capstone design projects. The faculty store on the website their interpretation of the data and document suggestions for improvements. The faculty, to see how curricular changes have made improvements to the data, monitor these suggestions. The

"Proceedings of the 2002 American Society of Engineering Education Annual Conference \& Exposition Copyright (C) 2002, American Society of Engineering Education 
data is marked to indicate that courses have been modified or added at a specific point in time in order to analyze the effect of the changes.

The website is organized according to the assessment model. See URL:

www.engr.ncsu.edu/assessment for access to the website. On the first page, click on the "Demo" section. The toolbar of buttons on the website, shown below, matches with the four parts of the model:

1. The documents under the Program Objectives button and the Program Outcomes button show how the program has defined its program mission, objectives, and outcomes;

2. The documents under the Assessment Plan button show the program's assessment plan, which was developed to assess the program objectives and outcomes. The Assessment Plan is linked with the documents under the Curricular Issues button and the Implementation button;

3. The Related Data button has all of the related data organized by data type and referenced according to the program's assessment plan; and

4. The documents which indicate how faculty have interpreted the data to determine program effectiveness and documents which show program improvements can be found under the Program Effectiveness button.

\begin{tabular}{|c|c|c|c|c|c|c|c|}
\hline $\begin{array}{c}\text { Program } \\
\text { Objectives }\end{array}$ & $\begin{array}{c}\text { Program } \\
\text { Outcomes }\end{array}$ & $\begin{array}{c}\text { Assessment } \\
\text { Plan }\end{array}$ & $\begin{array}{c}\text { Implement- } \\
\text { ation }\end{array}$ & $\begin{array}{c}\text { Curricular } \\
\text { Issues }\end{array}$ & $\begin{array}{c}\text { Related } \\
\text { Data }\end{array}$ & $\begin{array}{c}\text { Program } \\
\text { Effectiveness }\end{array}$ & Home \\
\hline
\end{tabular}

Figure 4: Website Toolbar Organization

Developing a website like this is similar to developing an electronic portfolio for the program. Six universities participating in the Urban Universities Portfolio Project (UUPP) funded by the Pew Charitable Trusts and sponsored by the American Association for Higher Education have found that developing institutional web portfolios have several benefits.

"We continue to be struck by the value to a campus of developing an institutional portfolio. The process can be a powerful vehicle for internal improvement and organizational development, leading to more widespread understanding of institutional mission and deeper commitment to educating students as effectively as possible...portfolio development fosters understanding of the need to generate and document evidence of effectiveness in carrying out the mission...Benefits include:

- Is more interactive and visual, and presents a greater variety of evidence, than paper reports.

- Serves as a catalyst for making assessment and improvement efforts more continuous, complete and cohesive.

- Presents a coherent view, with supporting evidence, of assessment and improvement efforts.

- Increases the visibility and value of key activities, including teaching and learning.

"Proceedings of the 2002 American Society of Engineering Education Annual Conference \& Exposition Copyright (C) 2002, American Society of Engineering Education 
- Promotes faculty development in ways compatible with the institution's mission." 15

What is of importance to note with the UUPP project is that an electronic gathering of information in a continuous, systematic way for use by faculty is an effective method for presenting a coherent view of assessment and improvement efforts. The goal of the NC State model and website project was to develop accessible assessment methods and tools and an electronic management system that integrates the various processes required for diverse student learning outcomes.

The process of creating a website is much like writing a paper. Before beginning, the process takes some brainstorming and creativity to design the layout of the entire site. ${ }^{16}$ The first step entails sketching the physical layout of the site from a design perspective, exploring several options that would make the front page of the website look visually attractive, professional and interesting. The NC State College of Engineering's Electronic Assessment Database website was created using Macromedia DreamWeaver UltraDev 4 and Macromedia Fireworks. While any HTML editing program would be sufficient, DreamWeaver is a very user-friendly package that makes the task of creating and editing web pages simple. Fireworks is a graphics package that easily integrates with DreamWeaver. The pages of the site were created as a template through DreamWeaver. By combining the template pages with data pages exported from SAS and Microsoft Excel, the Assessment Database website for the College of Engineering was built.

On the surface, the task of creating this website seemed challenging. However, this type of website is a project that nearly anyone can create with a little bit of time, a graphics program, and a simple HTML editor.

\section{Summary}

This paper has outlined the assessment model developed by the NC State University College of Engineering. This model provides a systematic, comprehensive tool for addressing program, and regional accreditation, as well as meets the needs of program faculty. With the implementation of the model with an electronic database on the web, faculty have continuous access to data and the documentation of the entire assessment process. Completion of the programmatic self-study during 2003-2004 should prove to be easier with this documentation in place.

\section{References}

1. "Principles of Accreditation," proposed by Commission on Colleges of the Southern Association of Colleges and Schools, 2001.

2. “2001-02 Engineering Criteria,” ABET, www.abet.org/criteria.html.

"Proceedings of the 2002 American Society of Engineering Education Annual Conference \& Exposition Copyright (c) 2002, American Society of Engineering Education 
3. Wright, B. , "Evaluating Learning in Individual Courses," in J.G. Gaff, J.L., Ratcliff, and Associates, Handbook Of The Undergraduate Curriculum: A Comprehensive Guide To Purposes, Structures, Practices And Changes, San Francisco: Jossey-Bass, 1997.

4. Palomba, C., and Banta, T., Assessment Essentials: Planning, Implementing, and Improving Assessment In Higher Education, San Francisco: Jossey-Bass, 1999.

5. Braskamp, L., "Purposes, Issues, and Principles of Assessment," NCA Quarterly, Fall, 1991.

6. Carter, M., Brent, R., and Rajala, S., "EC2000 Criterion 2: A Procedure for Creating, Assessing and Documenting Program Educational Objectives," Proceedings of the ASEE Annual Conference, Session 3530, 2001.

7. McGourty, J., Sebastian, C., and Swart, W., "Development of a Comprehensive Assessment Program in Engineering Education," Journal of Engineering Education, Vol. 87, No. 4, 355-361, 1998.

8. Nichols, J., The Departmental Guide to Implementation of Student Outcomes Assessment and Institutional Effectiveness, New York: Agathon Press, 1991.

9. Doepker, P., "The Development and Implementation of an Assessment Plan for Engineering Programs: A Model for Continuous Improvement," Proceedings of the ASEE Annual Conference, Session 1625, 1999.

10. Rogers, G., Personal correspondence. Rose-Hulman Institute of Technology, 2001.

11. Prus, J., and Johnson, R., "A Critical Review of Student Assessment Options," New Directions for Community Colleges, No. 88, 69-83, 1994.

12. Leonard, M., "Using Focus Groups to Gather Employer Information," www.succeednow.org, Tools for Accreditation Link.

13. Consolazio, G., Lindner, A., Pappas, E., and Legg, S., Project Succeed: Portfolio Assessment in Engineering, www.succeed.ufl.edu/library/portfolio assessment/, 2000.

14. The American Heritage Dictionary of the English Language, Fourth Edition, Boston: Houghton Mifflin Company, 2000.

15. "The Urban Universities Portfolio Project, 2000 Annual Report," www.imir.iupui.edu/portfolio/findings.htm.

16. Lynch, P. and Horton, S., "Web Style Guide,” www.info.med.yale.edu/caim/manual, 1997.

\section{Biographical Information}

\section{JONI E. SPURLIN, PH.D.}

Director of Assessment, College of Engineering, North Carolina State University. She has had 20 years experience in higher education and over 10 years of experience in assessment, evaluation, and institutional research. She provides leadership and expertise to faculty and staff in development and assessment of program objectives and outcomes.

"Proceedings of the 2002 American Society of Engineering Education Annual Conference \& Exposition Copyright (c) 2002, American Society of Engineering Education 
SARAH A. RAJALA, PH.D.

She received her Ph.D. in Electrical Engineering from Rice University in 1979. In July 1979, she joined the faculty at North Carolina State University, where she is currently Professor of Electrical and Computer Engineering and since 1996 has served as Associate Dean for Academic Affairs in the College of Engineering. Dr. Rajala's research interests include engineering education, the analysis and processing of images and image sequences.

JEROME P. LAVELLE, PH.D.

Assistant Dean of Academic Affairs in the College of Engineering at North Carolina State University. His interests include engineering education, engineering economic, engineering management, TQM and teamwork. He is coauthor of Engineering Economic Analysis, $8^{\text {th }}$ Edition, with Newman and Eschenbach and is past national division director of the engineering economy divisions of ASEE and IIE and engineering management division of ASEE.

\section{O. JEROME HOSKINS}

He is a junior in Computer Science and Mathematics undergraduate at North Carolina State University. He has developed the Assessment Website from conception to its present form. 